\title{
Dieta do Guaxinim (Procyon cancrivorus) no Parque Zoobotânico Arruda Câmara ${ }^{1}$
}

\author{
BATISTA, Cíntia Cleub Neves²
}

\author{
${ }^{1}$ Trabalho desenvolvido no Parque Zoobotanico Arruda Camara como parte da readequação das dietas dos \\ animais cativos no parque \\ ${ }^{2}$ Zootecnista - PZBAC, João Pessoa, Brasil \\ Email: cintiacleub@hotmail.com
}

RESUMO: O Guaxinim (Procyon cancrivorus) é um animal de hábito noturno e solitário, pode ser encontrado em mangues, várzeas, praias e matas ciliares, justificando, portanto, seu hábito alimentar onívoro e variado, composto principalmente por crustáceos, peixes, moluscos, frutos e sementes. No entanto, estudos direcionados a dietas de animais cativos ainda são bastante escassos, ocasionando frequentemente a oferta de dietas desbalanceadas e oferecidas em excesso, podendo causar obesidade e distúrbios nutricionais. Dessa forma, o trabalho em questão, objetou reformular a dieta do guaxinim cativo no Parque Zoobotânico Arruda Câmara, de forma que esta atenda as exigências nutricionais da espécie, promovendo uma melhor qualidade nutricional para o animal. A implementação da nova dieta foi feita de maneira gradativa, uma vez que a dieta anterior era composta em sua maioria por frutos e pequenas quantidades de carne bovina e ração para cachorros. Diante da variação de itens consumidos pelas espécies em vida livre, com modificações que dependem do habitat, buscou - se adequar uma dieta que atendesse as exigências da espécie, com melhor índice de aceitação e menor desperdício. Assim, a dieta que obteve melhor aceitação por parte dos animais foi composta por $40 \%$ de proteína animal, $50 \%$ de frutas e vegetais e $10 \%$ de ração para cachorros. Contudo, torna - se necessário ainda a realização de mais estudos a respeito das dietas de animais cativos, uma vez que estas podem variar consideravelmente de acordo com a região, tipo de recinto e comportamento do animal.

Palavras-chave: alimentação; animal cativo; conservação animal; procionídeos.

\section{INTRODUÇÃO}

Os procionídeos pertencem a Ordem Carnívora e estão subdivididos em duas subfamílias Procioninae e Ailurinae. Todos os procionídeos habitam o novo mundo, distribuídos tanto em regioes tropicais quanto neotropicais. Na America do Sul podem ser encontrados quatro gêneros, Procyon, Nasua, Potos e Bassaricyon (FAWLER E CUBAS, 2001).

$O$ guaxinim ou mão pelada (Procyon cancrivorus), como é popularmente conhecido é uma espécie amplamente distribuída, podendo ser encontrado em todos os biomas brasileiros, possui hábito solitário e noturno, é uma espécie considerada onívora, sendo descritos frequentemente em sua dieta, frutos, artrópodes, peixes, repteis, pequenos mamíferos e aves (CHEIDA et al, 2013).

É um animal de pequeno à médio porte, pensando de 3 à $15 \mathrm{~kg}$, podendo ser facilmente identificado em função da sua pelagem característica, possuindo uma mascara preta ao redor dos olhos, 
cauda longa, apresentando largos anéis escuros e amarelados, sua parte traseira é mais elevada que a dianteira e suas mãos são desprovidas de pelos, característica que deu origem ao seu nome popular no Brasil (SILVA, 1984; TEIXEIRA; AMBRÓSIO, 2007).

Apesar de serem classificados como animais onívoros, a dieta desses animais pode variar consideravelmente de acordo com o habitat em que se encontram, no sul e sudeste do pais o frutos representam grande parte da dieta dos guaxinins (PELLANDA et al., 2010; AGUIAR et al., 2011), podendo ser classificados

como

frugívoro/onívoro, já na caatinga os itens mais consumidos pelos $P$. cancrivorus foram os artrópodes representando $51,40 \%$ da dieta, seguido por frutos com $24,80 \%$ (DIAS E BOCCHIGLIERI, 2016).

Estudos relacionados a dieta de animais cativos, são insuficientes para a quantidade de animais mantidos atualmente nessa situação, sendo comumente encontrados estudos com animais em vida livre, em diferentes biomas. Sendo assim, a elaboração de dietas para animais mantidos em parques e zoológicos, são elaboradas baseadas apenas nesses estudos, contudo, essas dietas geralmente são ricas em energia, uma vez que animais em vida livre podem andar longas distancias em busca de alimento, diferindo dos animais mantidos em cativeiro, que não precisam se deslocar em busca de alimento e geralmente passam a maior parte do dia inativos, este fato demonstra a importância da elaboração de estudos direcionados a animais mantidos em cativeiro, de maneira que estes possam servir de embasamento teórico para outros profissionais que necessitem elaborar tais dietas.

Dessa forma, a presente pesquisa objetivou relatar a readequação da dieta do Guaxinim
(Procyon cancrivorus), cativo no Parque Zoobotânico Arruda Câmara.

\section{MATERIAL E MÉTODOS}

O presente trabalho foi desenvolvido no Parque Zoobotânico Arruda Câmara em João Pessoa, Paraíba e objetivou readequar a dieta do Guaxinim (Procyon concrivorus), cativo no parque.

Inicialmente a dieta do animal era composta por frutas, carne bovina e ração para cachorros, sem proporções devidamente especificadas, sendo sua maior parte composta por frutas. Dessa forma, buscou - se estabelecer quantidades específicas de cada item, de maneira que os parâmetros nutricionais sejam equilibrados, de modo que atenda as exigências nutricionais da espécie estudada.

Foram realizadas pesquisas bibliográficas de dietas de animais em vida livre e com o auxílio do software Zootrition foi feito o balanceamento da dieta para animais em cativeiro.

Foram testadas duas dietas, a primeira composta por $50 \%$ de proteína animal (carne, frango ou peixe) $30 \%$ de frutos (mamão, banana, maçã, melão, abacaxi, pepino e batata doce) e $20 \%$ de ração para cachorros, totalizando um aporte nutricional em média $31 \%$ de $\mathrm{PB}$, $3 \%$ de $\mathrm{FB}$ e $26 \%$ de EE.

A segunda dieta era composta por $40 \%$ de proteína animal (carne, frango ou peixe), $50 \%$ de frutas e vegetais (mamão, banana, maçã, melão, abacaxi, pepino e batata doce) e $10 \%$ de ração para cachorros, totalizando um aporte nutricional em média $27 \%$ de $\mathrm{PB}, 2,8 \%$ de $\mathrm{FB}$ e $25 \%$ de EE.

A readequação da dieta foi feita de maneira gradativa, de modo que os novos itens foram inseridos em pequenas quantidades e diariamente foi feito 0 acompanhamento do 
fornecimento e das sobras do que foi fornecido.

Para a realização deste trabalho os resultados descritos foram coletados durante 10 dias, onde, as bandejas eram preparadas diariamente conforme a descrição da dieta e pesada antes e após o fornecimento do alimento, além disso, foram feitas observações de comportamento de ingestão alimentar, para identificação dos itens preferenciais. Contudo, ressalta - se ainda, que estudos relacionados a dietas de animais cativos são feitos através de um trabalho de acompanhamento diário que deve ser feito durante toda a vida no animal, dessa forma, a dieta citada ainda continua sendo estudada, visando a melhoria na qualidade de vida e nutricional do animal.

\section{RESULTADOS E DISCUSSÃO}

Dentre as dietas apresentadas, a mais adequada e aceita pelo Guaxinim cativo foi a segunda. Contudo, a ração para cachorros não foi bem aceita, sendo coletadas diariamente sobras desse item. Ainda o animal demonstrou ainda preferência por peixe fresco, frutos (mamão e banana), carne bovina e frango.

PELLANDA et al (2010) estudando animais em vida livre no Sul do Brasil, encontraram uma dieta composta por $53 \%$ frutas e $47 \%$ itens de origem animal, já a dieta encontrada por DIAS E BOCCHIGLIERI (2015) no Nordeste do Brasil era composta por $51,40 \%$ de artrópode e os itens de origem vegetal somam apenas 33,90\%, sendo $24,80 \%$ representados por frutos.

QUINTELA et al (2014) sugerem ainda, que a dieta dos animais pode variar de acordo com o habitat em que vivem, fazendo uma comparação detalhada entre a dieta de animais que vivem em ambientes de restinga e estuarinos no Sul do Brasil, encontrando resultados divergentes, onde, na área de restinga o item mais consumido foi composto por frutos com 35,64\% seguido por insetos com 17,67\% e mamíferos com $11,43 \%$, já no ambiente estuarino o item mais consumido foi os mamíferos com 30,59\% seguido por frutos com $25,60 \%$ e crustáceos com $12,83 \%$.

FOWLER E CUBAS (2001) demonstram que a dieta utilizada em alguns zoológicos do Brasil para 0 Guaxinim (Procyon concrivorus) é composta basicamente por ração de cachorro, banana, maçã, batata doce, carne, ovos cozido, ratos, pintos de um dia e milho, apresentando bons resultados para animais em manutenção e reprodução, podendo ser adicionada ainda em pequenas quantidades, peixes, frutas e vegetais provendo maior palatabilidade e variedade da dieta.

Tais resultados demonstram a dificuldade encontrada na adequação da dieta de animais cativos, uma vez que de acordo os autores citados, as preferências alimentares dos animais variam consideravelmente de acordo com a disponibilidade de alimento no local e o habitat em que vivem, portanto, cabe aos técnicos responsáveis, estudar a melhor forma de suprir as necessidades nutricionais dos animais, aliando os estudos realizados com animais em vida livre e adequando para realidade dos animais cativos, considerando o comportamento do animal, recinto, clima e alimentos disponíveis no local.

\section{CONCLUSÃO}

Diante dos resultados obtidos no presente estudo, conclui-se que, o balanceamento das dietas dos animais cativos promove 0 fornecimento adequado de nutrientes que o animal precisa para sobreviver e manter seu estado saudável, bem como reduz o 
desperdício de alimentos gerados por dietas inadequadas.

Dessa forma, é de suma importância o desenvolvimento de mais estudos direcionados a dieta de animais cativos, uma vez que na literatura grande partes dos estudos são relacionados a animais em vida livre, que diversas vezes não condiz com a realidade dos animais mantidos em zoológicos.

Todavia, para a elaboração da dieta desses animais, torna - se imprescindível o acompanhamento diário do comportamento alimentar do animal, aliado a pesquisas bibliográficas e softwares de balanceamento de dietas, de maneira que os alimentos ofertados atendam tanto as suas exigências nutricionais, como promova saciação de maneira prazível.

\section{AGRADECIMENTOS}

A toda equipe de técnicos e tratadores do Parque Zoobotânico Arruda Câmara e a Secretaria Municipal do Meio Ambiente - SEMAM de João Pessoa, Paraíba pelo apoio.

\section{REFERÊNCIAS}

CHEIDA, C.C.; RODRIGUES, F.H.G. \& BEISIEGEL, B.M. (2013). Avaliação do risco de extinção do Guaxinim Procyon cancrivorus (Cuvier, 1798) no Brasil.

Biodiversidade Brasileira, 3(1):283-90

DIAS, D. M.; BOCCHIGLIERI, A. Dieta de carnívoros (Mammalia, Carnivora) em um remanescente de Caatinga, Nordeste do Brasil. Bioikos, Campinas, v. 29, n. 1 :13-19, jan./jun., 2015.

FOWLER, M. E.; CUBAS, Z. S. Biology, Medicine, and Surgery of South American Wild Animals. 1ed. $2001.563 \mathrm{p}$.

MARTINELLI, M. M.; VOLPI, T. A. Diet of racoon Procyon cancrivorus
(Carnivora, Procyonidae) in a mangrove and restinga area in Espirito Santo state, Brazil. Natureza on-line, v. 8, p. 150151, 2010.

PELLANDA, M.; ALMEIDA C.M.C.; SANTOS, M.F.M. \& HARTZ, S.M. (2010). Dieta do mão-pelada (Procyon cancrivorus, Procyonidae, Carnivora) no Parque Estadual de Itapuã, Sul do Brasil. Neotropical Biology and Conservation, 5(3):154-9.

\section{SILVA, F. 1984. Mamíferos Silvestres} do Rio Grande do Sul. Porto Alegre, Fundação Zoobotânica do Rio Grande do Sul, 246 p.

Teixeira, R.H.F. \& Ambrosio, S.R. 2007. Carnivora - Procyonidae (quati, mãopelada, jupará). Pp. 571-583. In: Cubas, Z.S.; Silva, J.C.R. \& Catão-Dias, J.L. (eds.). Tratado de animais selvagens: medicina veterinária. Roca, São Paulo. $1.354 \mathrm{p}$

QUINTELA, F. M., IOB, G., \& ARTIOLI, L. G. S. (2014). Dieta de Procyon cancrivorus (Carnivora, Procyonidae) em ambientes de restinga e estuarino no Sul do Brasil. Iheringia. Série Zoologia, 104(2), 143-149. https://doi.org/10.1590/1678-476620141 042143149

Agradecemos ao apoio da Fundação Araucária e da Coordenação de Aperfeiçoamento de Pessoal de Nível Superior - CAPES na realização do $3^{\circ}$ Workshop de Nutrição de Animais Selvagens.
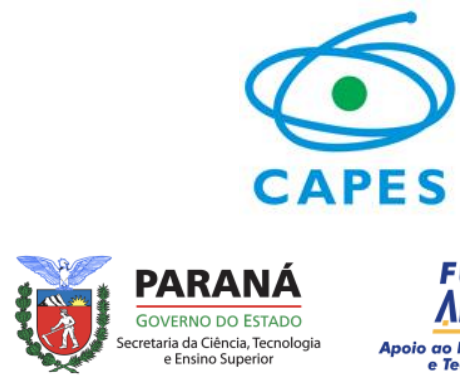

FUNDACÃO ARAUCARI io aosenvolvimento Cientifico 